\title{
IAU COLLOQUIUM No. 134 \\ NONLINEAR PHENOMENA IN STELLAR VARIABILITY
}

7 - 10 January 1992 held at Joyo Geibun Center, Mito, Japan

\section{Scientific Organizing Committee}

A. Baglin, M. Breger, J.-R. Buchler, W. Dziembowski, Yu. A. Fadeyev, H. Mori, Y. Osaki, J. Percy, H. L. Swinney,

M. Takeuti (chairperson), W. Unno

\section{Local Organizing Committee}

H. Ando, T. Hamada (chairperson), K. Saijo, M. Takeuti, Y. Tanaka

The colloquium was held with 77 registered participants from 14 countries. It was scientifically sponsored by IAU Commission 27 . The scientific program consisted of an opening talk, 20 invited reviews, 17 oral contributions, 29 posters, and a summary. The colloquium was held just after the disintegration of Soriet Union. Related with problems in the countries of the former Soviet Union, several astronomers did not succeed in participating the meeting. The papers sent by some of them to the Scientific Organizing Committee were presented to the participants as material for discussion. The titles and authors are listed below.

Yu. N. Efremov: The Cs Cepheids - orertone or first crossing?;

Larisa S. Kudashkina and Ivan L. Andronov: The multiperiodicities in the semi-regular variables;

Ivan L. Andronov: Autocorrelation function analysis of the rapid variability of the cataclysmic variables;

V. P. Arkhipova: Photometric evolution and the light oscillations of FG Sge in $196 i-1991$.

The colloquium was supported by several foundations and companies. We would like to express our thanks to the Commemorative Association for the Japan World Exposition (1970), the Science and Technology Promotion Foundation of Ibaraki, Fujitsu, Ltd., Hitachi Engineering Co. Ltd., Hitachi Tohoku Software Ltd., IBM Japan, Ltd., the Joyo Bank, the Joyo Geibun Center, the Mito Shinkin Bank, Mitsubishi Electric Corporation, NEC Corporation. Rikei Corporation, and the Astronomical Society of Japan for their support. We also express our thanks to Ibaraki University for its kind hospitality

T. Hamada and M. Takeuti 